\title{
MENGONTROL LAJU PELEPASAN KALOR PADA MODEL DINAMIK UNSUR UTAMA IKLIM
}

\author{
N. S. Wahyuni ${ }^{1}$, R. Ratianingsih ${ }^{2}$, A. I. Jaya ${ }^{3}$ \\ 1,2,3 Program Studi Matematika Jurusan Matematika FMIPA Universitas Tadulako \\ Jalan Soekarno-Hatta Km. 09 Tondo, Palu 94118, Indonesia. \\ 1Niluhsriwahyuni@rocketmail.com, 2,3ratianingsih@yahoo.com
}

\begin{abstract}
The caloric exchange rate in the atmosphere is one of the main causes of temperature and pressure changes. In order to control ok, the caloric exchange rate must be control. The effort is arranged to keep the interaction of the temperature and pressure normaly. In this study, the interaction among the temperature, pressure and concentration of $\mathrm{CO}_{2}$ are expressed in a mathematical model of main climate unsure in the form of nonlinear differential equations system. The problem of controlling the caloric exchange rate is considered as optimal control problem where the objective function is controlling the caloric exchange rate. Theoptimal solution of the controlled model is obtained by applying the minimum Pontryagin principle of heatwith the controller parameteru. The mathematical model is simulated to shows that the increasing of caloric exchange problem could overcome by controlling it with parametic controlled rate is $10 \%$.
\end{abstract}

\section{Keyword $\quad$ : Air Pressure, Calor, Minimum Pontryagin, Optimal Control, Temperature}

\section{ABSTRAK}

Laju pelepasan kalor di atmosfer merupakan salah satu yang menyebabkan perubahan suhu dan tekanan udara. Untuk mengendalikan laju pelepasan kalor di atmosfer dilakukan pengontrolan laju pelepasan kalor pada suhu dan tekanan udara. Usaha ini bertujuan untuk menjaga keseimbangan interaksi unsur-unsur utama iklim yaitu suhu dan tekanan udara. Dalam penelitian ini interaksi antara suhu $(T)$, tekanan udara $(P)$ dan konsentrasi karbon $(X)$ dinyatakan dalam model matematika dalam bentuk system persamaan diferensial tak linier. Masalah pengontrolan laju plepasan kalor diatmosfer dipandang sebagai masalah kontrol optimal dimana fungsi objektifnya adalah pengontrol laju pelepasan kalor pada suhu dan tekanan udara. Solusi optimal dari model pengontrolan laju pelepasan kalor di atmosfer diperoleh dengan menerapkan metode Minimum Pontryagin untuk menyelesaikan masalah kontrol optimal kalor pada suhu dan tekanan udaradengan parameter pengontrol $u$. Simulasi dari model matematika laju pelepasan kalor memperlihatkan bahwa peningkatan kalor di atmosfer dapat diatasi dengan tingkat pengontrolan laju pelepasan kalor pada suhu dan tekanan udara sebesar $10 \%$.

Kata Kunci $\quad$ : Kalor, Kontrol Optimal, Minimum Pontryagin, Suhu, Tekanan Udara 


\section{PENDAHULUAN}

Iklim di dunia selalu berubah, baik menurut ruang maupun waktu. Perubahan iklim adalah perubahan unsur-unsure iklim yang mempunyai kencenderungan naik atau turun secara nyata. Perubahan iklim global disebabkan oleh meningkatnya konsentrasi gas diatmosfer. Hal ini terjadi sejak revolusi industri yang membangun sumber energi yang berasal dari batu bara, minyak bumi dan gas yang membuang limbah gas di atmosfer seperti karbondioksida $\left(\mathrm{CO}_{2}\right)$, metana $\left(\mathrm{CH}_{4}\right)$, dan nitrous oksida $\left(\mathrm{N}_{2} \mathrm{O}\right)$.

Sang surya yang menyinari bumi juga menghasilkan radiasi panas yang ditangkap oleh atmosfer sehingga udara bersuhu nyaman bagi kehidupan manusia. Unsur-unsur iklim meliputi suhu dan tekanan udara merupakan unsur iklim yang utama (lin Sarvina, 2009).Matahari adalah sumber panas utama bagi bumi dan atmosfernya. Namun panas matahari yang sampai ke permukaan bumi berbeda-beda di setiap tempat. Hal ini menyebabkan suhu udara di setiap tempat berbeda-beda pula. Adapun faktor-faktor yang menyebabkan terjadinya perbedaan suhu yaitu datangnya sudut sinar matahari, tinggi rendahnya tempat, angin, arus laut, lamanya penyinaran, dan awan.

Tekanan udara adalah tekanan yang diberikan udara setiap satuan luas bidang datar dari permukaan bumi sampai batas atmosfer. Makin tinggi suatu tempat makin rendah kerapatan udaranya. Oleh karena itu, tekanan udara makin ke atas makin rendah. Adapun faktor-faktor yang mempengaruhi tekanan udara adalah tinggi rendahnya tempat dan temperatur.

Karbondioksida $\left(\mathrm{CO}_{2}\right)$ atau zat asam arang adalah sejenis senyawa kimia yang terdiri dari dua atom oksigen yang terikat secara kovalen dengan sebuah atom karbon. la berbentuk gas pada keadaan temperatur dan tekanan standar dan hadir di atmosfer bumi. Karbon dioksida adalah gas yang tidak berwarna dan tidak berbau. Ketika dihirup pada konsentrasi yang lebih tinggi dari konsentrasi karbon dioksida di atmosfer, ia akan terasa asam di mulut dan menyengat di hidung dan tenggorokan. Konsentrasi karbon dioksida bervariasi secara musiman. Di wilayah perkotaan, konsentrasi karbon dioksida secara umum lebih tinggi, sedangkan di ruangan tertutup, ia dapat mencapai 10 kali lebih besar dari konsentrasi di atmosfer terbuka.

Hubungan interaksi antara suhu, tekanan udara dan konsentrasi karbon di atmosfer akan dikaji dalam penelitian ini. Melalui hukum Thermodinamika yang ditinjau pada kondisi gas ideal (Jaya, A.I, 2011) menggambarkan interaksi antara suhu dan tekanan udara di atmosfer dalam bentuk sistem persamaan diferensial tak linear. Pengamatan terhadap kestabilan perluasan sistem tersebut menunjukkan adanya peran penting laju perubahan kalor sebagai penentu kestabilan sistem. Mengingat peran penting tersebut, maka pengontrolan laju perubahan kalor di atmosfer sangat perlu untuk dilakukan. 
Penelitian ini dilakukan untuk membangun pengontrol model matematika laju pelepasan kalor di atmosfer melalui prinsip minimum Pontryagin. Prinsip minimum Pontryagin merupakan suatu metode yang dapat digunakan untuk memperoleh penyelesaian kontrol optimal yang sesuai dengan tujuan (meminimumkan performance index). Prinsip ini dapat digunakan untuk menyelesaikan persamaan linear dan nonlinear.

\section{METODE PENELITIAN}

Penelitian ini bersifat kajian kuantitatif terhadap SPD linear dengan menggunakan Metode Minimum Pontryagin. Adapun langkah - langkah pengontrolan optimum adalah sebagai berikut:
a. Menentukan fungsi tujuan
b. Menentukan fungsi Hamilton
c. Sistem memenuhi persamaan state, co-state, dan kondisi stationer.
d. Mensubtitusi hasil yang didapatkan dari kondisi stationer ke sistem.
e. Simulasi
f. Kesimpulan

\section{HASIL DAN PEMBAHASAN}

\subsection{Model Matematika Unsur Utama Iklim}

Metode ini merupakan kajian terhadap model dinamik unsur utama iklim yang dilakukan dengan menentukan pengontrol optimal dari model matematika unsur utama iklim pada persamaan di bawah ini:

$\dot{T}=\frac{Q\left[\alpha P Q+C_{p}-T Q\right]}{C_{p}\left[C_{p}-K \alpha-Q\right]}$

$\dot{P}=\frac{Q[K-P Q]}{\left[C_{p}-K \alpha-Q\right]}$.

$\dot{X}=b\left(\frac{T}{P}\right)(1-c X)-\frac{e X}{1+X}$

dengan $C_{p}=36,775 \mathrm{~J} / \mathrm{mol} \mathrm{K}, K=0,23, \alpha=2,36$ (Ratianingsih,2011)

\subsection{Pengontrolan Laju Pelepasan Kalor}

1. Pengontrolan Suhu $(\mathrm{T})$

Pengontrolan pada model dinamik unsur utama iklim yang dilakukan dengan meminimumkan laju pelepasan kalor untuk mengendalikan suhu dilakukan dengan membangunperfomance index sebagaiberikut:

$J(u)=\frac{1}{2} \int_{t_{0}}^{t_{a}}\left(A_{1} u_{1}^{2}+A_{2} T^{2}\right)$ 
2. Pengontrolan Tekanan Udara $(P)$

Pengontrolan pada model dinamik unsur utama iklim yang dilakukan dengan meminimumkan laju pelepasan kalor untuk mengendalikan tekanan udara dilakukan dengan membangun performance index sebagai berikut:

$J(u)=\frac{1}{2} \int_{t_{0}}^{t_{a}}\left(A_{1} u_{2}^{2}+A_{2} P^{2}\right)$

3. Pengontrolan Suhu $(T)$ dan Tekanan Udara $(P)$ secara Bersamaan

Pengontrolan pada model dinamik unsur utama iklim yang dilakukan dengan meminimumkan laju pelepasan kalor untuk mengendalikan suhu dan tekanan udara secara bersamaan dilakukan dengan membangun perfomance index sebagai berikut:

$J(u)=\frac{1}{2} \int_{t_{0}}^{t_{a}}\left(A_{1} u_{1}^{2}+A_{1} u_{2}^{2}+A_{2} T^{2}+A_{3} P^{2}\right)$.

\subsection{Model Pengontrol Laju Pelepasan Kalor}

1. Model Pengontrol Laju Pelepasan Kalor dengan Pengontrol Suhu ( $T$ )

$\begin{aligned} & \operatorname{Min} J(u)=\frac{1}{2} \int_{t_{0}}^{t_{a}}\left(A_{1} u_{2}^{2}+A_{2} P^{2}\right) \\ & \text { dengan kendala }\end{aligned}$

$$
\begin{gathered}
\dot{T}=\frac{\partial H}{\partial \lambda_{1}}=\frac{Q\left[\alpha P Q+C_{p}-\left(1-u_{1}\right) T Q\right]}{C_{p}\left[C_{p}-K \alpha-Q\right]} \\
\dot{P}=\frac{\partial H}{\partial \lambda_{2}}=\frac{Q[K-P Q]}{\left[C_{p}-K \alpha-Q\right]} \\
\dot{X}=\frac{\partial H}{\partial \lambda_{3}}=b\left(\frac{T}{P}\right)(1-c X)-\frac{e X}{1+X}
\end{gathered}
$$

2. Model Pengontrol Laju Pelepasan Kalor dengan Pengontrol Tekanan Udara $(P)$

$$
\begin{gathered}
\operatorname{Min} J(u)=\frac{1}{2} \int_{t_{0}}^{t_{a}}\left(A_{1} u_{2}^{2}+A_{2} P^{2}\right) \\
\text { dengan kendala } \\
\dot{T}=\frac{\partial H}{\partial \lambda_{1}}=\frac{Q\left[\alpha P Q+C_{p}-T Q\right]}{C_{p}\left[C_{p}-K \alpha-Q\right]} \\
\dot{P}=\frac{\partial H}{\partial \lambda_{2}}=\frac{Q\left[K-\left(1-u_{2}\right) P Q\right]}{\left[C_{p}-K \alpha-Q\right]} \\
\dot{X}=\frac{\partial H}{\partial \lambda_{3}}=b\left(\frac{T}{P}\right)(1-c X)-\frac{e X}{1+X}
\end{gathered}
$$

3. Model Pengontrol Laju Pelepasan Kalor dengan Pengontrol Suhu $(T)$ dan Tekanan Udara $(P)$ secara Bersamaan 


$$
\left.\begin{array}{c}
\operatorname{Min} J(u)=\frac{1}{2} \int_{t_{0}}^{t_{a}}\left(A_{1} u_{1}^{2}+A_{1} u_{2}^{2}+A_{2} T^{2}+A_{3} P^{2}\right) \\
\text { dengan kendala } \\
\dot{T}=\frac{\partial H}{\partial \lambda_{1}}=\frac{Q\left[\alpha P Q+C_{p}-\left(1-u_{1}\right) T Q\right]}{C_{p}\left[C_{p}-K \alpha-Q\right]} \\
\dot{P}=\frac{\partial H}{\partial \lambda_{2}}=\frac{Q\left[K-\left(1-u_{2}\right) P Q\right]}{\left[C_{p}-K \alpha-Q\right]} \\
\dot{X}=\frac{\partial H}{\partial \lambda_{3}}=b\left(\frac{T}{P}\right)(1-c X)-\frac{e X}{1+X}
\end{array}\right\}
$$

\subsection{Penyelesaian Optimal Kontrol}

Hal pertama yang dilakukan untuk menyelesaikan optimal kontrol adalah dengan menentukan fungsi Hamilton.

1. Penyelesaian Optimal Kontrol dari Model Laju Pelepasan Kalor dengan Pengontrol

Suhu $(T)$

Untuk persamaan (7) diperoleh sebagai berikut :

$H=f(x, u, t)+\lambda g(x, u, t)$

$$
\begin{aligned}
& H=\frac{1}{2} A_{1} u_{1}^{2}+\frac{1}{2} A_{2} T^{2}+\lambda_{1}\left(\frac{Q\left[\alpha P Q+C_{p}-\left(1-u_{1}\right) T Q\right]}{C_{p}\left[C_{p}-K \alpha-Q\right]}\right)+\lambda_{2}\left(\frac{Q[K-P Q]}{\left[C_{p}-K \alpha-Q\right]}\right) \\
& +\lambda_{3}\left(b\left(\frac{T}{P}\right)(1-c X)-\frac{e X}{1+X}\right)
\end{aligned}
$$

Dari persamaan Hamilton diperoleh persamaan state, co-state dan kondisi stasioner sebagai berikut :

a. Kondisi State

$$
\begin{aligned}
& \dot{T}=\frac{\partial H}{\partial \lambda_{1}}=\frac{Q\left[\alpha P Q+C_{p}-\left(1-u_{1}\right) T Q\right]}{C_{p}\left[C_{p}-K \alpha-Q\right]}, T(0)=T \geq 0 \\
& \dot{P}=\frac{\partial H}{\partial \lambda_{2}}=\frac{Q[K-P Q]}{\left[C_{p}-K \alpha-Q\right]}, P(0)=P \geq 0 \\
& \dot{X}=\frac{\partial H}{\partial \lambda_{3}}=b\left(\frac{T}{P}\right)(1-c X)-\frac{e X}{1+X}, X(0)=X \geq 0
\end{aligned}
$$

b. Persamaan co-state

$$
\begin{aligned}
& \dot{\lambda_{1}}=-\frac{\partial H}{\partial T}=-A_{2} T-\frac{\lambda_{1} Q\left(-\left(1-u_{1}\right) Q\right)}{C_{P}\left(C_{P}-K \alpha-Q\right)}-\frac{\lambda_{3} b(1-c X)}{P} \\
& \dot{\lambda_{2}}=-\frac{\partial H}{\partial P}=-\frac{\lambda_{1} Q(\alpha Q)}{C_{P}\left(C_{P}-K \alpha-Q\right)}-\frac{\lambda_{2} Q(-Q)}{\left(C_{P}-K \alpha-Q\right)}+\frac{\lambda_{3} b T(1-c X)}{P^{2}} \\
& \dot{\lambda_{3}}=-\frac{\partial H}{\partial X}=-\lambda_{3}\left(-\frac{b T c}{P}-\frac{e}{1+X}+\frac{e x}{(1+X)^{2}}\right)
\end{aligned}
$$


C. Kondisi Stasioner

$\frac{\partial H}{\partial u_{1}}=0$, Dengan kondisi batas $0,1 \leq u \leq 0.9$, sehingga diperoleh

$u_{1}=\operatorname{maks}\left\{\min \left[\frac{\frac{\lambda_{1} Q(T Q)}{C_{P}\left(C_{P}-K \alpha-Q\right)}}{A_{1}}, 0.9\right] 0,1\right\}$

2. Penyelesaian Optimal Kontrol dari Model Laju Pelepasan Kalor dengan Pengontrol Tekanan Udara $(P)$

Untuk persamaan (8) diperoleh sebagai berikut:

$H=f(x, u, t)+\lambda g(x, u, t)$

$H=\frac{1}{2} A_{1} u_{2}^{2}+\frac{1}{2} A_{2} P^{2}+\lambda_{1}\left(\frac{Q\left[\alpha P Q+C_{p}-T Q\right]}{C_{p}\left[C_{p}-K \alpha-Q\right]}\right)+\lambda_{2}\left(\frac{Q\left[K-\left(1-u_{2}\right) P Q\right]}{\left[C_{p}-K \alpha-Q\right]}\right)$

$+\lambda_{3}\left(b\left(\frac{T}{P}\right)(1-c X)-\frac{e X}{1+X}\right)$

Dari persamaan Hamilton diperoleh persamaan state, co-state dan kondisi stasioner sebagai berikut :

a. Kondisi State

$$
\begin{aligned}
& \dot{T}=\frac{\partial H}{\partial \lambda_{1}}=\frac{Q\left[\alpha P Q+C_{p}-T Q\right]}{C_{p}\left[C_{p}-K \alpha-Q\right]}, T(0)=T \geq 0 \\
& \dot{P}=\frac{\partial H}{\partial \lambda_{2}}=\frac{Q\left[K-\left(1-u_{2}\right) P Q\right]}{\left[C_{p}-K \alpha-Q\right]}, P(0)=P \geq 0 \\
& \dot{X}=\frac{\partial H}{\partial \lambda_{3}}=b\left(\frac{T}{P}\right)(1-c X)-\frac{e X}{1+X}, X(0)=X \geq 0
\end{aligned}
$$

b. Persamaan co-state

$$
\begin{aligned}
& \dot{\lambda_{1}}=-\frac{\partial H}{\partial T}=-\frac{\lambda_{1} Q(-Q)}{C_{p}\left[C_{p}-K \alpha-Q\right]}-\frac{\lambda_{3} b(1-c X)}{P} \\
& \dot{\lambda_{2}}=-\frac{\partial H}{\partial P}=-A_{2} P-\frac{\lambda_{1} Q(\alpha Q)}{C_{P}\left(C_{P}-K \alpha-Q\right)}-\frac{\lambda_{2} Q\left(-\left(1-u_{2}\right) Q\right)}{\left(C_{P}-K \alpha-Q\right)}+\frac{\lambda_{3} b T(1-c X)}{P^{2}} \\
& \dot{\lambda_{3}}=-\frac{\partial H}{\partial X}=-\lambda_{3}\left(-\frac{b T c}{P}-\frac{e}{1+X}+\frac{e x}{(1+X)^{2}}\right)
\end{aligned}
$$

c. Kondisi Stasioner

$\frac{\partial H}{\partial u_{2}}=0$, Dengan kondisi batas $0,1 \leq u \leq 0.9$, sehingga diperoleh

$$
u_{2}=\operatorname{maks}\left\{\min \left[\frac{\frac{\lambda_{2} Q(P Q)}{\left(C_{P}-K \alpha-Q\right)}}{A_{1}}, 0.9\right] 0,1\right\}
$$


3. Penyelesaian Optimal Kontrol dari Model Laju Pelepasan Kalor dengan Pengontrol Suhu $(T)$ dan Tekanan Udara $(P)$ secara Bersamaan

Untuk persamaan (9) diperoleh sebagai berikut :

$$
\begin{aligned}
& H=f(x, u, t)+\lambda g(x, u, t) \\
& H=\frac{1}{2} A_{1} u_{1}^{2}+\frac{1}{2} A_{2} u_{2}^{2}+\frac{1}{2} A_{3} T^{2}+\frac{1}{2} A_{4} P^{2}+\lambda_{1}\left(\frac{Q\left[\alpha P Q+C_{p}-\left(1-u_{1}\right) T Q\right]}{C_{p}\left[C_{p}-K \alpha-Q\right]}\right) \\
& +\lambda_{2}\left(\frac{Q\left[K-\left(1-u_{2}\right) P Q\right]}{\left[C_{p}-K \alpha-Q\right]}\right)+\lambda_{3}\left(b\left(\frac{T}{P}\right)(1-c X)-\frac{e X}{1+X}\right)
\end{aligned}
$$

Dari persamaan Hamilton diperoleh persamaan state, co-state dan kondisi stasioner sebagai berikut :

a. Kondisi State

$$
\begin{aligned}
& \dot{T}=\frac{\partial H}{\partial \lambda_{1}}=\frac{Q\left[\alpha P Q+C_{p}-\left(1-u_{1}\right) T Q\right]}{C_{p}\left[C_{p}-K \alpha-Q\right]}, T(0)=T \geq 0 \\
& \dot{P}=\frac{\partial H}{\partial \lambda_{2}}=\frac{Q\left[K-\left(1-u_{2}\right) P Q\right]}{\left[C_{p}-K \alpha-Q\right]}, P(0)=P \geq 0 \\
& \dot{X}=\frac{\partial H}{\partial \lambda_{3}}=b\left(\frac{T}{P}\right)(1-c X)-\frac{e X}{1+X}, X(0)=X \geq 0
\end{aligned}
$$

b. Persamaan co-state

$$
\begin{aligned}
& \dot{\lambda_{1}}=-\frac{\partial H}{\partial T}=-A_{3} T-\frac{\lambda_{1} Q\left(-\left(1-u_{1}\right) Q\right)}{C_{p}\left[C_{p}-K \alpha-Q\right]}-\frac{\lambda_{3} b(1-c X)}{P} \\
& \dot{\lambda_{2}}=-\frac{\partial H}{\partial P}=-A_{4} P-\frac{\lambda_{1} Q(\alpha Q)}{C_{P}\left(C_{P}-K \alpha-Q\right)}-\frac{\lambda_{2} Q\left(-\left(1-u_{2}\right) Q\right)}{\left(C_{P}-K \alpha-Q\right)}+\frac{\lambda_{3} b T(1-c X)}{P^{2}} \\
& \dot{\lambda_{3}}=-\frac{\partial H}{\partial X}=-\lambda_{3}\left(-\frac{b T c}{P}-\frac{e}{1+X}+\frac{e x}{(1+X)^{2}}\right)
\end{aligned}
$$

c. Kondisi Stasioner

$\frac{\partial H}{\partial u_{1}}=0, \frac{\partial H}{\partial u_{2}}=0$, Dengan kondisi batas $0,1 \leq u \leq 0.9$, sehingga diperoleh

$u_{1}=\operatorname{maks}\left\{\min \left[\frac{\frac{\lambda_{1} Q(T Q)}{C_{P}\left(C_{P}-K \alpha-Q\right)}}{A_{1}}, 0.9\right] 0,1\right\}$ dan $u_{2}=\operatorname{maks}\left\{\min \left[\frac{\frac{\lambda_{2} Q(P Q)}{\left(C_{P}-K \alpha-Q\right)}}{A_{2}}, 0.9\right] 0,1\right\}$

\subsection{Simulasi}

Penyelesaian optimal kontrol ini menggunakan program Matlab yang mendefinisikan masalah optimal kontrol dengan parameter yang diketahui. 
Tabel 1 : Parameter dan Nilainya

\begin{tabular}{|c|c|}
\hline Parameter & Nilai \\
\hline$Q$ & 1.98 \\
\hline$\alpha$ & 2.36 \\
\hline$C_{p}$ & 36.775 \\
\hline$K$ & 0.23 \\
\hline$A_{1}, A_{2}, A_{3}$ & 1 \\
\hline$B$ & 0.1 \\
\hline$E$ & 0.1 \\
\hline$C$ & 0.1 \\
\hline
\end{tabular}

Sumber : (Moh. Afandi, 2015)

Tabel 2 : Parameter Komputasi

\begin{tabular}{|c|c|c|}
\hline Parameter Komputasi & Simbol & Nilai \\
\hline Waktu Awal & $t_{0}$ & 2015 \\
\hline Waktu Akhir & $t_{1}$ & 2017 \\
\hline Batas Kontrol & $u_{1}$ & 0.1 \\
\hline Batas Kontrol & $u_{2}$ & 0.1 \\
\hline Suhu & $T$ & 33 \\
\hline Tekanan & $P$ & 1.98 \\
\hline Konsentrasi Karbon & $X$ & 339 \\
\hline
\end{tabular}

Sumber : (Moh. Afandi, 2015)

1. Simulasi dari Model Laju Pelepasan Kalor dengan Pengontrol Suhu (T)

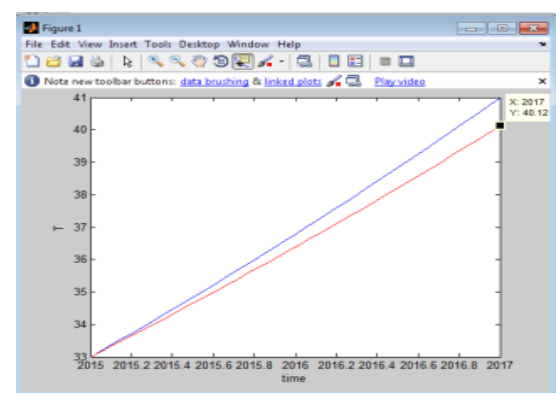

(a)

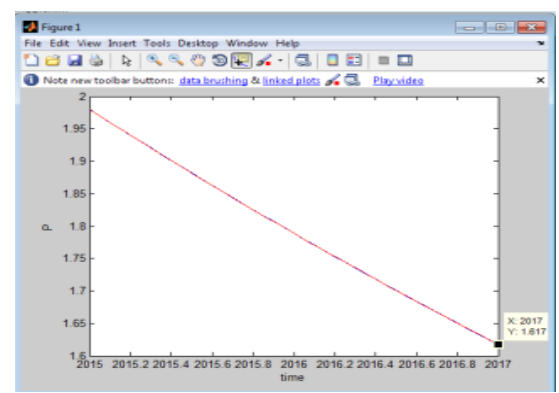

(b)

Gambar 1 : suhu dan tekanan udara (a) sebelum dikontrol dan (b) sesudah dikontrol

Pada gambar 1 memperlihatkan simulasi pengontrolan pelepasan kalor dengan pengontrol suhu. Dimana gambar ini menunjukkan suhu selama 2 tahun. Pada grafik yang berupa garis berwarna biru menunjukan besarnya suhu sebelum dikontrol misalnya tahun 2017 suhu 40,77 derajat celcius dan grafik yang berupa garis 
berwarna merah menunjukan besarnya suhu sesudah dikontol misalnya tahun 2017 suhu 40,12. Pengontrol ini mengakibatkan tekanan udara mengalami penurunan. Misalkan pada tahun 2017 tekanan udara yang terjadi adalah 1,617 atm.

2. Simulasi dari Model Laju Pelepasan Kalor dengan Pengontrol Tekanan Udara $(P)$

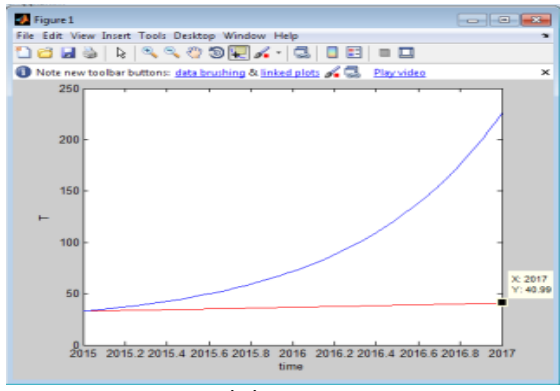

(a)

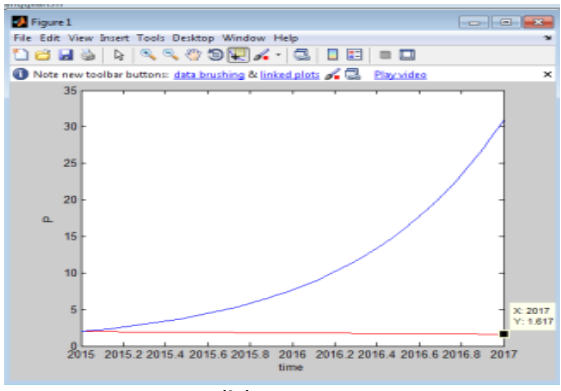

(b)

Gambar 2 : suhu dan tekanan udara (a) sebelum dikontrol dan (b) sesudah dikontrol

Gambar 2 memperlihatkan simulasi pengontrolan pelepasan kalor dengan pengontrol tekanan udara. Dimana gambar ini menunjukan tekanan udara selama 2 tahun. Pada grafik yang berupa garis berwarna biru menunjukkan besarnya tekanan udara sebelum dikontrol naik sangat cepat misalnya tahun 2017 yaitu 30,99 atm dan grafik yang berupa garis berwarna merah menunjukan besarnya tekanan udara sesudah dikontrol menurun misalnya tahun 2017 yaitu 1,617. Pengontrol ini mengakibatkan suhu mengalami peningkatan yaitu \pm 40 ,99 derajat celcius pada tahun 2017 tetapi peningkatannya ini masih berada pada interval yang diinginkan.

3. Simulasi dari Model Laju Pelepasan Kalor dengan Pengontrol Suhu $(T)$ dan Tekanan Udara $(P)$ secara Bersamaan
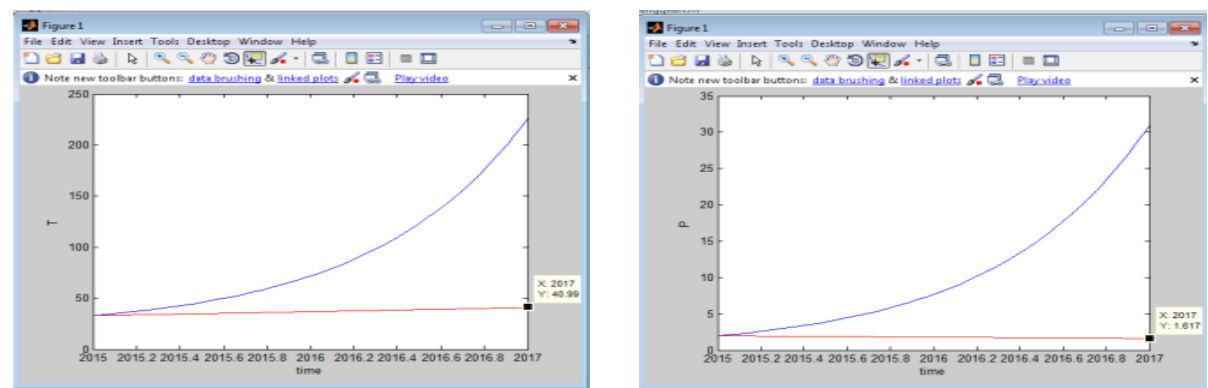

Gambar 3 : suhu dan tekanan udara yang dikontrol bersamaan 
Gambar 3 memperlihatkan simulasi pengontrolan pelepasan kalor dengan pengontrol suhu dan tekanan udara secara bersamaan. Dimana gambar ini menunjukan penelitian selama 2 tahun. Pada grafik yang berupa garis berwarna biru menunjukkan besarnya suhu dan tekanan udara sebelum dikontrol naik sangat cepat misal tahun 2017 yaitu suhu naik 226 derajat celcius dan tekanan udara naik 30,99 atm dan grafik yang berupa garis berwarna merah menunjukan besarnya suhu dan tekanan udara sesudah dikontrol, suhu meningkat 40,99 derajat celcius tetapi masih dalam interval yang di inginkan dan tekanan udara menurun 1,617 atm.

\subsection{Pembahasan}

Hasil yang diperoleh pada gambar 1 memperlihatkan bahwa dengan mengontrol laju pelepasan kalor di atmosfer dapat menekan laju perubahan suhu di atmosfer. Dimana suhu sebelum dikontrol meningkat sedangkan ketika sesudah dikontrol suhu tetap meningkat tetapi peningkatannya masih dapat dijaga dalam interval yang diinginkan. Pada gambar 2 juga memperlihatkan bahwa dengan mengontrol laju pelepasan kalor di atmosfer dapat menekan laju perubahan tekanan udara di atmosfer. Ketika belum dikontrol tekanan udara sangat cepat naiknya tetapi ketika sesudah dikontrol tekanan udara mengalami penurunan. Dan pada gambar 3 memperlihatkan pengontrolan pada suhu dan tekanan udara secara bersamaan. Dimana diperoleh hasilnya yaitu ketika suhu dan tekanan udara belum dikontrol terjadi peningkatan yang sangat cepat, tetapi suhu ketika dikontrol tetap meningkat tetapi masih dalam interval yang diinginkan sedangkan tekanan udara mengalami penurunan saat sudah dikontrol. Dalam penelitian ini dapat disimpulkan bahwa ketika pengontrolan dilakukan pada suhu, suhu mengalami peningkatan dan tekanan udara mengalami penurunan. Tetapi keduaduanya masih terkontrol pada interval yang diinginkan. Sedangkan pengontrolan pada tekanan udara mengakibatkan tekanan udara terkontrol dan suhu secara otomatis ikut terkontrol juga. Adapun untuk pengontrolan suhu dan tekanan udara secara bersamaan mendapatkan hasil yang sama dengan pengontrolan pada tekanan udara saja. Jadi pengontrolan suhu dan tekanan udara secara bersamaan tidak harus dilakukan.

\section{KESIMPULAN}

Berdasarkan penelitian yang telah dilakukan dapat disimpulkan bahwa:

1. Pengontrol optimal dari model dinamik unsur utama iklim paling baik adalah dengan melakukan pengontrolan pada $T$ dan $P$ yaitu dengan meminimalisir laju pelepasan kalor di atmosfer.

2. Pengontrolan optimal dari model dinamik unsur utama iklim ditentukan dengan :

a) Membangun performance index untuk meminimumkan laju pelepasan kalor di atmosfer. 
b) Menyelesaikan persamaan optimal kontrol yang dilakukan dengan menentukan fungsi Hamilton

c) Fungsi Hamilton memberikan persamaan state, co-state, dan kondisi stationer.

d) Mensubtitusi optimal kontrol yang diperoleh dalam keadaan state.

3. Dalam penelitian ini dapat disimpulkan bahwa ketika pengontrolan dilakukan pada suhu, suhu mengalami peningkatan dan tekanan udara mengalami penurunan. Tetapi kedua-duanya masih terkontrol pada interval yang diinginkan. Sedangkan pengontrolan pada tekanan udara mengakibatkan tekanan udara terkontrol dan suhu secara otomatis ikut terkontrol juga. Adapun untuk pengontrolan suhu dan tekanan udara secara bersamaan mendapatkan hasil yang sama dengan pengontrolan pada tekanan udara. Jadi pengontrolan suhu dan tekanan udara secara bersamaan tidak harus perlu dilakukan.

\section{DAFTAR PUSTAKA}

[1]. Jaya A.I. 2011. Mencari Perluasan Model Dinamaik Unsu - unsur Utama Iklim. JIMT,Vol.8,No.1. Palu.

[2]. Murdiyarso, D. 2003. Konvensi Perubahan Iklim. Buku Kompas. Jakarta.

[3]. Naidu, Desineni Subbaram. 2002. Optimal Control System. Idaho State Univesity. Pacatello. Idaho USA.

[4]. Ratianingsih. 2011. Dynamic Model of Pressure, Temperature and $\mathrm{CO}_{2}$ Concentration: Identification of Stability Parameters Potency. Proceeding of International Conference of The 6-th SEAMS-GMU 2011.

[5]. Subiono. 2013. Sistem Linear dan Kontrol Optimal. ITS. Surabaya. 